\title{
Особенности стратегий и тактик проектирования в музыкальном образовании
}

\author{
Константинова Н.В. \\ Алтайский государственный институт культуры, \\ Россия, 656065, г. Барнаул, ул. Юрина, 277 \\ E-mail: konst40.24@gmail.com
}

\begin{abstract}
Аннотация. Проектировочная деятельность становится необходимым компонентом подготовки современного педагога-музыканта. Развитие педагогической науки и практики, появление новых технологий создаёт необходимость постоянного переосмысления возможностей проектировочной деятельности, что недостаточно освещено в научно-педагогической литературе. Целью работы стало рассмотрение системы музыкального образования, как целостного компонента проектирования, а также музыкально-педагогического процесса, как его части с позиций взаимодействие трёх субъектов: учитель - музыка - ученик. Дано пояснение содержания каждого. Изучен опыт проектирования системы музыкального образования на примере анализа проекта «Музыка для всех» в Республике Саха (Якутия). Представлен анализ педагогической ситуации, имеющей эстетический характер, как основного объекта тактики проектирования, её содержания, структуры, этапов организации в музыкально-педагогическом процессе. Определены формы проектирования в музыкально-образовательной практике. Приведены условия создания благоприятной педагогической среды в реализации проектной деятельности педагога-музыканта. Изложенные позиции позволят ориентироваться и адаптироваться к постоянно развивающимся и меняющимся педагогическим знаниям, ускорят адаптацию к новым музыкально-образовательным технологиям, новым парадигмам образования. Научным вкладом данной работы стало обоснование проектирования с позиций специфики взаимодействия учитель - музыка - ученик.
\end{abstract}

Ключевые слова: проектирование, система, музыкально-педагогический процесс, эстетические ситуации, художественный диалог.

Для цитирования: Константинова Н.В. 2020. Особенности стратегий и тактик проектирования в музыкальном образовании. Вопросы журналистики, педагогики, языкознания, 39 (3): 399-407. DOI 10.18413/2712-7451-2020-39-3-399-407

\section{Pedagogical strategies and tactics designing in music learning}

\author{
Natalia V. Konstantinova \\ Altai State Institute of Culture, \\ 277 Yurina St, Barnaul, 656065, Russia
}

\begin{abstract}
Design activity is becoming a necessary component of the training of a modern music teacher. The development of pedagogical science and practice, the emergence of new technologies creates the need for a constant rethinking of the possibilities of design activities, which is insufficiently covered in the scientific and pedagogical literature. The aim of the work was to consider the system of music education as an integral component of design, as well as the musical and pedagogical process, as its part from the standpoint of the interaction of three subjects: teacher - music - student. An explanation of the content of each is given. The experience of designing a music education system was studied on the example of analyzing the project "Music for All" in the Republic of Sakha (Yakutia). The analysis of the pedagogical situation, which has an aesthetic character, as the main object of design tactics, its content, structure, stages of organization in the musical and pedagogical process is presented. The forms of design in musical and educational practice are determined. The
\end{abstract}


conditions for creating a favorable pedagogical environment in the implementation of project activities of a musician teacher are given. The stated positions will allow one to orientate and adapt to constantly developing and changing pedagogical knowledge, accelerate adaptation to new musical and educational technologies, new paradigms of education. The scientific contribution of this work was the substantiation of the design from the standpoint of the specifics of the teacher-music-student interaction.

Keywords: design, system, musical and pedagogical process, aesthetic situations, artistic dialogue.

For citation: Konstantinova N.V. 2020. Features of design strategies and tactics in music education. Questions of journalism, pedagogy, and linguistics, 39 (3): 399-407 (in Russian). DOI 10.18413/27127451-2020-39-3-399-407

\section{Введение}

Изучение вопросов подготовки педагога-музыканта расширило и углубило представления о характере формирования основных профессиональных качеств выпускников высшей школы. В ряде работ [Абдуллин и др., 2002; Абдуллин, 2014; Дитер Дёрренбехер, 2009; Киреева, 2011; Рачина, 2015] указывается, что в профессию должен прийти специалист, способный творчески решать самые разнообразные задачи, готовый к участию в научно-исследовательской и проектной деятельности, разработке инновационных идей, способствующих продуктивно осуществлять педагогическую работу в системе музыкального образования. Вопросы педагогического проектирования освещаются в работах Безруковой В.С. [1994], Бичеровой Е.Н. [2012], Ганиевой Э.А. [2017], Пахомовой Н.Ю. [2003], Яковлевой Н.О. [2001] и др. Рачина Б.С. [2015] выделяет умения осуществлять проектную деятельность как профессиональную компетенцию будущего педагогамузыканта.

Историко-педагогические аспекты проектирования наиболее полно описаны в статье О.Е. Лебедевой [2010]. Автор, ссылаясь на работы В.М. Розина, справедливо отмечает, что предпосылки возникновения данного вида деятельности относятся ещё к античности. Так постепенно термин «проектирование» пришёл в педагогику из технического знания. В этой области проект означал создание предстоящего продукта, то есть того, что будет сделано в будущем. Подобная работа требовала особого внимания и расчёта каждой детали, чтобы в процессе его изготовления избежать ошибки.

В музыкальной педагогике, как и в общей педагогике, проектировочная деятельность связана с планированием результатов музыкального обучения, музыкального развития, музыкального воспитания в системе взаимодействия учитель - ученик - музыка. Этим взаимодействием и обусловлена специфика проектирования, так как не всегда можно с точностью до деталей предугадать особенность воздействия музыкального искусства на учащихся.

Сложность связана со следующими факторами: а) музыка по своей природе эмоциональна; б) в основе музыкальной деятельности лежит активное восприятие музыки, которое пронизывает все виды музыкальной деятельности, обуславливая неразрывность единства всего музыкально-образовательного процесса; в) обучение музыке - это, в первую очередь, обучение пониманию мира эмоций и чувств; г) в предметном поле педагогамузыканта лежит процесс общения, как правило, со способными, а иногда одаренными учащимися, которые подвержены сиюминутным творческим фантазиям, где есть место вдохновению и импровизации.

Неслучайно в музыкальной педагогике чаще используются методические разработки уроков, занятий, концертов и т.д. Именно в них представлены примерные планы работы, намечены основные направления в выстраивании взаимоотношений между учителем и учащимися. Методическая разработка более свободна по своему содержанию, она содержит в себе возможности индивидуального авторского прочтения определённой педагоги- 
ческой проблемы. Однако в современном музыкальном образовании расширяется педагогическое знание, методы и приёмы музыкального обучения и воспитания, появляются новые технические средства, позволяющие транслировать музыкальное искусство в слушательскую аудиторию, развиваются формы музыкально-просветительской практики, растёт потребность в разнообразных формах общения с музыкой различных социальных аудиторий. Всё это требует более детального и тщательного рассмотрения, предельного внимания к мелочам в предстоящей деятельности. Джон Дьюи в своей работе «Демократия и образование» подчёркивает постоянную необходимость обновления жизни, которая продиктована новыми потребностями [The Project Gutenberg..., 2008]. Все эти положения создают проблемное поле научно-методической реальности, отражающей осмысление проектировочной деятельности в современном музыкальном образовании и требующей решения конкретных задач музыкально-педагогической практики. Этим обусловлена необходимость обращения к вопросам особенностей проектирования стратегий и тактик в музыкальном образовании.

Целью исследования является выявление особенностей стратегии и тактик проектирования в деятельности педагога-музыканта. Объектом исследования выступает проектировочная деятельность в музыкальном образовании, предметом - стратегии и тактики проектирования.

\section{Основная часть}

Б.С. Рачина [2015] в проектировании выделяет стратегию и тактику как объединяющее звено в планировании образовательной деятельности педагога-музыканта. Рассмотрим их особенности.

Начнём с того, что именно проектирует педагог-музыкант. Основными составляющими его стратегии являются объекты проектирования [Безрукова, 1994], а именно система музыкального обучения, музыкально-педагогический процесс и непосредственно ситуации, которые в нём встречаются. Именно понимание роли педагогических ситуаций и их возможного содержательного наполнения позволят педагогу-музыканту более точно осмыслить предстоящую деятельность, наполненную творческими идеями, новыми образами, и, как следствие, новыми результатами. Музыкально-педагогический процесс состоит из различных ситуаций, которые позволяют увидеть переход из одного эмоционального состояния в другое. Этим он напоминает музыкальную форму, которая состоит из мотивов, фраз, периодов, частей. Педагогические ситуации входят в процесс, процесс в систему.

Система музыкального образования - это целостное единство всех факторов, способствующих достижению поставленных целей музыкального обучения, развития и воспитания человека. Это комплекс задач, принципов, знаний о музыке, музыкальных знаний, музыкальных умений, навыков, видов музыкальной деятельности, методов, аспектов взаимодействия музыки с другими видами искусства и т.д. Весь этот комплекс обозначает качественное состояние музыкального образования. В системе должно быть обязательным наличие связей и зависимостей между всеми компонентами, входящими в неё. Важно в проектировании и наличие ведущей идеи, которая бы объединяла всю деятельность педагога-музыканта и учащихся в системе, и наличие ведущего звена, которым может стать сам учащийся, его способности, потребности, приоритеты, интересы, склонности и другие возможности.

Интересен в этом отношение опыт проектирования системы музыкального образования в Республике Саха (Якутия). Проект «Музыка для всех» начал реализовываться в республике с 2013 года и по настоящее время достойно развивается. Это национальный межотраслевой проект, разработанный на всех уровнях образовательной практики: от детского сада до вуза. Главной идеей проекта стала концепция Д.Б. Кабалевского, связанная с признанием воспитательного потенциала музыкального искусства. Проект разработан на основе взаимодействия двух ведомств: Министерства образования и науки и Министер- 
ства культуры и духовного развития Республики Саха (Якутия). Детально проработана структура подобного взаимодействия, создан Попечительский совет проекта, межведомственная коллегия, республиканский организационный комитет по реализации проекта, научно-методический совет проекта и т.д. Разработана модель взаимодействия различных ведомств и организаций, которые помогают реализовать данную идею в практику, определены задачи каждого звена, рассмотрена финансовая сторона реализации проекта. Его создатели уверены, что музыкальное развитие ребёнка - та сила, которая переменит устоявшееся состояние и будет способствовать формированию и развитию нового мышления молодого поколения [Харайбатова, 2019]. В настоящий момент разработчики и организаторы данного проекта создают новые площадки для масштабирования идеи на других территориях Российской Федерации.

В данном примере проект «Музыка для всех» является стратегическим. В нём указан конечный результат, ожидаемый от внедрения музыкальных занятий на всех уровнях образовательной деятельности, разработаны, смоделированы механизмы для мотивации всех структур, необходимых для реализации данного проекта, обозначены уровни (концептуальный, научно-методический, управленческий, образовательный и др.). Ещё одним важным стратегическим этапом является разработка музыкально-педагогического процесса, в котором важно учитывать все компоненты структуры, объекты и субъекты образовательной деятельности. Музыкально-педагогический процесс проектируется исходя из цели обучения для каждого отдельно взятого учащегося или каждой отдельно взятой группы.

Скажем, необходимо провести музыкально-просветительскую работу в определённой аудитории учащихся в течении длительного времени для получения конкретного результата. Педагог-музыкант мысленно отбирает музыкальный материал, влияющий на активизацию познавательного интереса, способы его трансляции в определённую возрастную и социально-ориентированную аудиторию, выстраивает собранный материал по степени устойчивости внимания слушателей, обдумывает выводы и обобщения по каждой встрече, продумывает возможные средства аудио и видео презентации и т.д. Далее необходимо учитывать особенности восприятия музыки в каждой отдельно взятой аудитории, возможное время звучания и время общения со слушателями. Посредством установления таких зависимостей, например, можно ликвидировать противоречия в восприятии музыкального произведения - те противоречия, которые мешают углубить изучение возможностей самого слушателя, ослабить или усилить его мотивацию в общении с музыкальным искусством и занятиям определённой музыкальной деятельностью.

Любую стратегию обеспечивает тактика, которую невозможно проектировать без рассмотрения педагогической ситуации в каждом конкретно взятом случае музыкальнопедагогического процесса. Эта маленькая клеточка концентрирует в себе все достоинства и недостатки процесса и системы в целом. Так, если в результате реализации того или иного музыкально-образовательного проекта возникают конфликтные ситуации и их количество довольно большое, это значит, что система и процесс, который в неё входит, изначально порочны.

Структура педситуации внешне проста. В.С. Безрукова отмечает, что «эта простота обманчива» [Безрукова, 1994, с. 104]. Взаимодействие в триаде учитель - ученик - музыка строится как реализация сложного эмоционального мира. Например, педагог хочет снять напряжение в отношениях с учащимся. Он проектирует ситуации, в которых этот учащийся смог бы проявить себя как человек интересный, способный, талантливый и т.д. Очень важно подобрать то музыкальное произведение, которое бы способствовало раскрытию внутреннего мира обучаемого, мотивации к последующему общению с музыкой. Для этого он использует методы доверия, поощрения, выступления. Помимо музыкального сочинения, при проектировании педагогических ситуаций важно выбрать метод взаимодействия, например, методы доверия, поощрения, планирования выступлений. 
Педагогические ситуации могут возникать стихийно или предварительно проектироваться. Но и те, что возникли стихийно, разрешаются продуманно, с предварительным проектированием выхода из них. Особенность проектирования педагогической ситуации состоит в том, что, будучи интегративной по сути, она одна и даже набор ситуаций не могут заменить ни форму, ни систему в педагогике. Нельзя из ситуаций создать форму, как нельзя из форм создать педагогическую систему. В этом заключается чрезвычайная сложность любых педагогических явлений. Проектирование педагогических ситуаций происходит как процесс «подгонки» педагогического процесса под конкретных людей, оперативного учёта реальной обстановки в её мельчайших звеньях.

Педагогические ситуации в музыкальном образовании носят эстетический характер, целью их проектирования становится музыкально-эстетическое развитие человека. Тактика проектирования ситуаций построена на речевом общении и проектируются в определённой логике, предусматривая несколько этапов: ориентировочноподготовительный, художественно-конструктивный, художественно-аналитический. На каждом из этих этапов ситуация рассматривается как проблемная, так как творчество связано с новым решением, неординарным выходом из поставленных задач. Данная ситуация активизирует процесс музыкального обучения, причём процесс активизации двойственный, он непредсказуем и для обучаемых, и для педагога. Информация должна не преподноситься в готовом виде, а провоцировать личность на собственное отношение к происходящей деятельности, на поиск средств для её преобразования.

Ориентировочно-подготовительный этап связан с пониманием педагогоммузыкантом «неизвестного», которое лежит в основе проектирования определённых ситуаций. Неизвестным может выступить творческая задача, в которой содержится новое знание, подлежащее усвоению, которое не даётся в готовом виде, его следует добывать самим учащимся. Далее важно продумать средства, которые вызывают желание, мотивацию к «добыче» неизвестных знаний, способов действия, пробуждению интереса и т.д. Такими средствами может стать музыкальный материал, который лежит в основе педагогически комфортной среды.

Художественно-конструктивный этап подразумевает проектирование конкретной музыкальной деятельности, составления диалога о музыке. Причём это не просто познавательная вопросно-ответная форма общения - это должен быть художественный диалог, в центре которого находится музыкальное искусство. Важную роль в проектировании данного этапа выполняют символы невербальной коммуникации, а именно: мимика, пантомимика, жестикуляция, качества звучания речи (громкость, темп, паузы, эмоциональная окрашенность и т.д.). В качестве активного собеседника В.В. Медушевский включает в диалог учителя и ученика «духовное "Я" ("Мы") произведения как "вечный" неотменимый субъект музыки, основой которого оказываются "логосы бытия", проявляющиеся в умосозерцании, умном видении, интуитивно-интеллектуальном осмыслении жизни» [Медушевский, 1993, с. 81]. В художественном диалоге проектируются не только вопросы, но и мысленно прогнозируются и фиксируются возможные ответы. Подобный подход позволяет направлять размышления обучаемых на самостоятельные выводы и суждения. Вопрос, с одной стороны, должен направлять творческую активность учащихся в нужное русло, не позволяя им уклоняться в сторону под влиянием не имеющих отношения к звучащей музыке случайных ассоциаций, а с другой - оставлять каждому достаточно свободы для выражения собственной точки зрения в анализе осмысляемой музыки.

Художественно-аналитический этап подразумевает рефлексию по поводу общения с музыкой и новых мыслей, состояний, которые переживались в совместном творческом действии. Подобная тактика выстраивания должна учитывать возможности обучаемых, которые обладают различным уровнем музыкальной подготовки и опытом общения с музыкальным искусством. Поэтому творческие задачи для каждого обучаемого обязательно должны быть различны с учётом способностей, социальных условий, уровня подготовки, 
мотивации и т.д. Важно учитывать, как долго, в каком темпе, где проектируется та или иная ситуация. Необходимо адаптировать все действия педагога-музыканта на конкретного учащегося, его мировоззрение, интересы, склонности, возможности.

Педагогическое проектирование, если оно профессионально, всегда связано со стремлением педагога организовать для своих учащихся такую среду обучения и внеучебной деятельности, в которой они полнее раскрывали бы свой внутренний мир, были бы свободны, достигали успеха и чувствовали себя комфортно [Константинова, 2018]. Подобная образовательная среда была рассмотрена в работах Джона Дьюи [Dewey J. Froebel`s Educational Principles, 1915]. Автор подчёркивал, что для организации благоприятной психосоциальной среды необходимы следующие признаки:

- доброжелательная атмосфера;

- поощрение инициативности, творчества;

- взаимопонимание, признание альтернативных точек зрения;

- признание человеческих ценностей;

- преобладание стремления к самостоятельности, активности, интеллектуальному и личностному росту;

- общность идей, интересов;

- развитие определённых традиций и др.

Эти признаки в процессе проектирования могут найти своё проявление в различных формах музыкального образования: урок, занятие, кружок, беседы о музыке, музыкальные лектории, инновационные музыкально-образовательные проекты и т.д. Важно, чтобы все формы были наполнены ярким, эмоциональным содержанием, приносили радость, проводились в атмосфере продуктивного творчества или сотворчества, уважения интересов каждого из участников [Константинова, 2020].

Как компонент самостоятельной работы педагога-музыканта проектировочная деятельность реализуется в виде разработки творческих внеклассных мероприятий, циклов бесед о музыке для школьников, инновационных проектов и др. [Константинова, 2019б]. И в том и в другом случае она должна быть ориентирована на сознательные, целенаправленные и самостоятельные действия самого обучающегося, на творческое развитие научных (педагогических, психологических, музыкальных и т.п.) знаний и умений, на овладение методологией научного музыкально-педагогического творчества [Константинова, 2019а].

\section{Выводы}

Рассмотрены вопросы, профилактики возможных негативных последствий проектировочной деятельности в музыкальном образовании. Актуальной профессиональной средой для её изучения стало взаимодействие трёх субъектов: учитель - музыка - ученик. Обоснование проектирования с позиций подобного взаимодействия и стало научным вкладом данной работы. Рассмотрение особенности стратегий и тактик педагогического проектирования во многом обусловлены спецификой самого музыкального искусства, его восприятием, умением выстраивать художественный диалог и продумыванием в нём всех деталей вербального выражения своих чувств и эмоций, позволяющих увидеть положительное воздействие на формирующие, развивающие и воспитательные процессы музыкально-образовательной практики.

Однако сам процесс проектирования представляет собой сложное явление, а потому в рамках данной работы анализ стратегий и тактик только обозначил данную проблему и её смысловые единицы. В то же время представляется, что изложенные позиции позволят ориентироваться и адаптироваться к постоянно развивающимся и меняющимся педагогическим знаниям, ускорят адаптацию к новым образовательным технологиям, новым парадигмам образования. 


\section{Список источников}

1. Абдуллин Э.Б. 2014. Основы исследовательской деятельности педагога-музыканта. СПб., Планета музыки, 368 с.

2. Абдуллин Э.Б., Ванилихина О.В., Морозова Н.В. 2002. Методологическая культура педагога-музыканта. М., Академия, 272 с.

3. Безрукова В.С. 1994. Педагогика : учебник для индустр.-пед. техникумов и инж.-пед. Вузов. Екатеринбург, УГППУ, 338 с.

4. Пахомова Н.Ю. 2003. Метод учебных проектов в образовательном учреждении. Под ред. Н.Ю. Пахомовой. М., АРКТИ, 121 с.

5. Рачина Б.С. 2015. Педагогическая практика: подготовка педагога-музыканта. Под ред. Б.С. Рачиной. СПб., Лань, Планета музыки, 512 с.

6. Основы теоретического музыкознания. 2003. Под ред. М.И. Ройтерштейна. М., Академия, 2003, 272 с.

7. Харайбатова О.М. 2019. Организационная структура управления Республиканским проектом «Музыка для всех». Ежеквартальный культурно-просветительский журнал «Музыка для всех», 2: 24-26.

8. Яковлева Н.О. 2001. Педагогическое проектирование. Под ред. И.С Карасовой. Челябинск, Изд-во Челяб. гос. пед. ун-та, 124 с.

\section{Список литературы}

1. Лебедева О.Е. 2010. Педагогическое проектирование: теоретические аспекты. В кн. Аграрная наука - сельскому хозяйству. V Международная научно-практическая конференция. Барнаул, Алтайский государственный аграрный университет: 466-468.

2. Бичерова Е.Н. 2012. Особенности исследовательской и проектной деятельности младших школьников: сравнительно-сопоставительный анализ. Вестник Брянского государственного университета, 1 (1): 187-194.

3. Ганиева Э.А. 2017. Проектно-исследовательская деятельность обучающихся в рамках ФГОС второго поколения: сравнительно-сопоставительный анализ. В кн.: Культура, наука, образование: проблемы и перспективы. Материалы VI международной научно-практической конференции, Нижневартовск, 13-15 февраля 2017 г., ч. I: Общественные и гуманитарные науки. Под ред. А.В. Коричко. Нижневартовск, Изд-во Нижневарт. гос. ун-та: 38-45.

4. Константинова Н.В. 2020. Особенности взаимодействия вузов культуры с Центрами помощи детям, оставшимся без попечения родителей (на примере деятельности музыкального факультета АГИК). В кн.: Взаимодействие учреждений культуры и образования в музыкальном развитии детей. Сборник статей и материалов IV Всероссийской научно-практической конференции, Новосибирск, 5-6 марта 2020 г. Новосибирск, Изд-во Новосиб. гос. консерватория им. М.И. Глинки: 32-40.

5. Константинова Н.В. 2019а. Особенности проектно-исследовательской деятельности педагога-музыканта. В кн.: Теория, история и практика образования в сфере культуры. Материалы XIX международной научно-методической конференции, Барнаул, 17 октября 2019 г. Под ред. Е.А. Московкиной. Барнаул, Изд-во АГИК: 166-169.

6. Константинова Н.В. 2019б. Традиционные и инновационные формы общения с музыкой в современном образовании. В кн.: Взаимодействие учреждений культуры и образования в музыкальном развитии детей. Сборник статей и материалов III Всероссийской научнопрактической конференции, посвящённой 115-летию со дня рождения Дмитрия Борисовича Кабалевского, Новосибирск, 1-2 марта 2019 г. Под ред. Л.П. Робустовой. Новосибирск, Изд-во Новосиб. гос. консерватория им. М.И. Глинки: 29-37.

7. Константинова Н.В. 2018. Культурно-воспитательная среда как условие профессиональнотворческого саморазвития студентов. В кн.: Теория, история и практика образования в сфере культуры. Материалы XVIII международной научно-методической конференции, Барнаул, 15 марта 2018 г. Под ред. Л.Г. Гусляковой. Барнаул, Изд-во АГИК: 115-118.

8. Медушевский В.В. 1993. Художественный мир музыки. В кн.: Спутник учителя музыки. Под ред. С.С. Балашовой. М., Просвещение: 77-89. 
9. Dieter Dörrenbächer 2009. Musikalische bildung in deutschland von kindesbeinen an Ziele Strukturen - Perspektiven. URL: https://rachmaninov.ru/assets/uploads/konf/dgt_2016/dyorrenbexer.pdf (дата обращения: 23.05.2020).

10. Dewey J. 1915. Froebel`s Educational Principles. URL: http://www.brocku.ca /MeadProject/Dewey/Dewey-1907/Dewey-1915b.html. Chicago: University of Chicago. (1915): 111-127. (дата обращения: 05.05.2020).

11. Кірєєва Т.І. 2011. Музична освіта сьогодення: від ярослава мудрого до новітнього часу URL: http://dspace.nbuv.gov.ua/bitstream/handle/123456789/85447/26-Kireeva.pdf?sequence=1 (дата обращения: 03.06.2020).

12. The Project Gutenberg E Book of Democracy and Education, by John Dewey. 2008. URL:http://www.gutenberg.org/files/852/852-h/852-h.htm (дата обращения: 03.05.2020).

\section{References}

1. Lebedeva O.E. 2010. Pedagogicheskoe proektirovanie: teoreticheskie aspekty [Pedagogical Designing: Theoretical Aspects]. In: Agrarnaja nauka - sel'skomu hozjajstvu [Agrarian Science to Farming Industry]. V international scientific and practical conference. Barnaul, Altai state agrarian University. Barnaul: 466-468.

2. Bicherova E.N. 2012. Osobennosti issledovatel'skoy i proektnoy deyatel'nosti mladshikh shkol'nikov: sravnitel'no-sopostavitel'nyy analiz [Features of research and design activity younger schoolboys: the rather-comparative analysis]. The Bryansk State University Herald, 1 (1): 187-194.

3. Ganieva E.A. 2017. Proektno-issledovatel'skaya deyatel'nost' obuchayushchikhsya v ramkakh FGOS vtorogo pokoleniya: sravnitel'no-sopostavitel'nyy analiz [Project and Research Activities of Students within the frames of Federal State Educational Standard of the Second Generation]. In: Kul'tura, nauka, obrazovanie: problemy i perspektivy [Culture, science, education: problems and prospects]. Materialy VI mezhdunarodnoy nauchno-prakticheskoy konferentsii, Nizhnevartovsk, 13-15 fevralya 2017 g., ch. I: Obshchestvennye i gumanitarnye nauki. Ed. A.V. Korichko. Nizhnevartovsk, Publ. Izd-vo Nizhnevart. gos. un-ta,: 38-45.

4. Konstantinova N.V. 2020. Osobennosti vzaimodeystviya vuzov kul'tury s Tsentrami pomoshchi detyam, ostavshimsya bez popecheniya roditeley (na primere deyatel'nosti muzykal'nogo fakul'teta AGIK) [Peculiarities of interaction between cultural universities and Centers for helping children without parental care (on the example of the activity of the music faculty of ASIC)]. In: Vzaimodeystvie uchrezhdeniy kul'tury i obrazovaniya v muzykal'nom razvitii detey [The interaction of cultural and educational institutions in the musical development of children]. Sbornik statey i materialov IV Vserossiyskoy nauchno-prakticheskoy konferentsii, Novosibirsk, 5-6 marta 2020 g. Novosibirsk, Publ. Izd-vo Novosib. gos. konservatoriya im. M.I. Glinki: 32-40.

5. Konstantinova N.V. 2019a. Osobennosti proektno-issledovatel'skoy deyatel'nosti pedagogamuzykanta [Features of the design and research activities of the teacher-musician]. In: Teoriya, istoriya i praktika obrazovaniya $\mathrm{v}$ sfere kul'tury [Theory, history and practice of education in the field of culture]. Materialy XIX mezhdunarodnoy nauchno-metodicheskoy konferentsii, Barnaul, 17 oktyabrya 2019 g. Ed. E.A. Moskovkinoy. Barnaul, Publ. Izd-vo AGIK: 166-169.

6. Konstantinova N.V. 2019в. Traditsionnye i innovatsionnye formy obshcheniya s muzykoy v sovremennom obrazovanii [Traditional and innovative forms of communication with music in modern education]. In: Vzaimodeystvie uchrezhdeniy kul'tury i obrazovaniya v muzykal'nom razvitii detey [The interaction of cultural and educational institutions in the musical development of children]. Sbornik statey i materialov III Vserossiyskoy nauchno-prakticheskoy konferentsii, posvyashchennoy 115-letiyu so dnya rozhdeniya Dmitriya Borisovicha Kabalevskogo, Novosibirsk, 1-2 marta 2019 g. Ed. L.P. Robustovoy. Novosibirsk, Publ. Izd-vo Novosib. gos. konservatoriya im. M.I. Glinki: 29-37.

7. Konstantinova N.V. 2018. Kul'turno-vospitatel'naya sreda kak uslovie professional'notvorcheskogo samorazvitiya studentov [Cultural and educational environment as a condition for professionally-creative self-development of students]. In: Teoriya, istoriya i praktika obrazovaniya v sfere kul'tury [Theory, history and practice of education in the field of culture]. Materialy XVIII mezhdunarodnoy nauchno-metodicheskoy konferentsii, Barnaul, 15 marta 2018 g. Ed. L.G. Guslyakovoy. Barnaul, Publ. Izd-vo AGIK: 115-118. 
8. Medushevskiy V.V. 1993. Spetsifika iskusstva. Sushchnost' i spetsifika muzyki [The specifics of art. The essence and specificity of music]. In: Sputnik uchitelya muzyki [Music teacher companion]. Ed. S.S. Balashovoy. M., Publ. Prosveshchenie: 64-68.

9. Dieter Dörrenbächer 2009. Musical education in Germany from childhood to goals structures - perspectives. URL: https://rachmaninov.ru/assets/uploads/konf/dgt_2016/dyorrenbexer.pdf (date of the application: 23.05.2020).

10.Dewey J. 1915. Froebel`s Educational Principles. URL: http://www.brocku.ca /MeadProject/Dewey/Dewey-1907/Dewey-1915b.html; Chicago: University of Chicago. (1915): 111127. (date of the application: 05.05.2020).

11.Kireeva T.I. 2011. Musical Education of Our Time: from Yaroslav the Wise to Modern Times URL: http://dspace.nbuv.gov.ua/bitstream/handle/123456789/85447/26-Kireeva.pdf?sequence=1 (access date: 03.06.2020).

12.The Project Gutenberg E Book of Democracy and Education, by John Dewey. 2008. URL:http://www.gutenberg.org/files/852/852-h/852-h.htm (date of the application: 03.05.2020).

\section{ИНФОРМАЦИЯ ОБ АВТОРЕ}

Константинова Наталья Владимировна, кандидат педагогических наук, доцент, заведующая кафедрой музыкознания и фортепиано Алтайского государственного института культуры, г. Барнаул, Россия

\section{INFORMATION ABOUT THE AUTHOR}

Natalia V. Konstantinova, Candidate of Pedagogical Sciences, Associate Professor, head of the Department of musicology and piano of the Altai state Institute of culture, Barnaul, Russia 